\title{
Climatic change, refugia, and biodiversity: where do we go from here? An editorial comment
}

\author{
Anthony D. Barnosky
}

Received: 18 May 2007 / Accepted: 8 August 2007 / Published online: 24 November 2007

(C) Springer Science + Business Media B.V. 2007

\begin{abstract}
Climate change in the coming century will affect biodiversity at many biological levels, ranging from ecosystems to genes. Forecasting the effects of these changes, especially in the context of which species will be restricted to refugia and/or prone to extinction, is taking on increasing importance. Enhanced integration of phylogeography with phylochronology, paleontological and geological data, and climate science (especially taking into account scales of climate change other than orbitally-induced glacialinterglacial cycles) is needed to more fully appreciate the genetic effects of past climate changes, and to help predict future fates of species.
\end{abstract}

In this issue, an exchange by Stewart and Dalén (2008) and Pruett and Winker (2008) highlights an emerging problem: how will accelerated rates of climatic change over the next hundred years (IPCC 2007) influence the generation and maintenance of biodiversity? And how will we know?

The differing opinions of the respective authors arise from Pruett and Winker's (2005) interpretation of how so-called 'cryptic refugia' in Beringia (the contiguous land mass that connects Siberia and Alaska when sea level falls during glacial times) led to the genetic patterning they observed in rock sandpipers, birds whose geographic range is near coastal areas. Stewart and Dalén, on the other hand, argue for the possibility that it is today's sandpipers that are locked in an interglacial refugium, and that their range was larger and more southerly during glacial times.

The debate brings to the forefront some key matters that biologists must confront before we can reliably interpret how (or if) refugia and climatic change interact to maintain biodiversity at the genetic level, and what that means for the persistence of taxa and ultimately ecosystems. These key matters include (1) more attention to the varying scales of cyclic or at least periodic climatic change that potentially generate and maintain diversity; (2) more rigor in specifying the climatic and distributional hypotheses that phylogeographic data are used to test, and clear specification of what observations would reject or uphold the hypotheses; (3) recognition that methods such as Time-to-Most-Recent-Common-Ancestor

\footnotetext{
A. D. Barnosky $(\bowtie)$

Department of Integrative Biology and Museums of Paleontology and Vertebrate Zoology, University of California, Berkeley, CA 94720, USA

e-mail: barnosky@berkeley.edu
} 
(TMRCA) do not produce estimates of divergence times sufficiently resolved to distinguish between many different competing hypotheses of what caused the divergence; (4) attention to differentiating between in situ diversification vs. effects of ecological sorting and population movement; and (5) better integration of independent paleoclimatic, geologic, and paleontologic records that exist to test phylogeographic hypotheses.

The important consideration about scales of climate cycling, alluded to but not explicitly addressed in the sandpiper exchange, is that embedded within the orbitally driven glacialinterglacial cycles are shorter term climatic cycles such as Heinrich events and DansgaardOeschger events. In turn, the glacial-interglacial events themselves are cycles embedded in even longer climate cycles, for example, low-frequency Milankovitch modulations that manifest with approximately 1.2 million and 2.4 million year periodicities (van Dam et al. 2006, and many other studies summarized in Ruddiman 2001). It is presently unknown which, if any, of these cycles is most important in producing and maintaining genetic diversity, and ultimately, higher taxonomic diversity. Despite this, the implicit assumption in many phylogeographic studies (the sandpiper ones included) is that the key is to be found in the glacial-interglacial cycles, particularly the most recent one(s). A difficult problem is that, with cycling, what happens to populations in one part of the cycle (say, an interglacial when the geographic range of a cold-adapted species is reduced to small, isolated populations) may be erased in the next part of the cycle (a glacial when the populations of the cold-adapted species expand again and most regain haplotype diversity). The key question is how long does a cycle have to last in order for the genetic signal that arises in one part of the cycle to become fixed such that it is not erased in the next part of the cycle - those lasting changes are the important ones for predicting the effects of climatic change on diversity. Teasing them out requires interpreting phylogeographic data in the context of many different possible scales of cyclic climatic change, rather than assuming that only the last one or two orbital-scale cycles are telling the main story. The strongest evidence probably will come from using the data to reject the importance of certain cycling scales or individual cycles.

The sandpiper debate also nicely illustrates that for significant progress to be made, it will be necessary to interpret phylogeographic data in the context of a temporally and spatially constrained hypothesis of climatic change, and effects of certain climate parameters on the habitat of the species. The opposing exchanges go part way down that road by specifying different models of refugia: on the one hand assuming a model of glacial ranges for the sandpipers being more restricted than interglacial ranges, and on the other, a model that assumes wider interglacial ranges. However, to effectively test either model, a suite of boundary conditions has to be articulated. For example, what is the magnitude and duration of the climatic change of interest? Is it the change encompassed in the transition from a glacial to an interglacial? Or is it the time through maximum ice advance within a glacial? Is the climatic parameter of interest seasonality, temperature, or some other parameter? Are physical changes to the landscape involved, such as position and extent of glaciers, or sea level changes? How would these changes be expected to affect geographic range size and shape given what is known about the life history of the study organisms? Specifying such information then leads to specific models of how biogeographic ranges would be expected to expand or contract, and what the attendant predictions for genetic structuring among populations would be. For example, for sandpipers in Beringia, one could envision lowered sea level during glacial times that would expand island size and coastal area and reduce distance between islands, which would lead to the prediction that sandpiper habitat would expand then. How does the genetic structuring fit? And do we need climatic change to explain it, or would the observed structure also be 
consistent with predictions of island biogeographic theory without climatic change? Without such specification, a wide variety of interesting interpretations of the observed genetic structuring are possible, but none stand more robustly than others.

The third issue illustrated by the sandpiper debate is that coalesence-based estimates of TMRCA at best define a broad window of time in which a divergence between two populations initiated. For example, the sandpiper TMRCA calculated for four successive branching points that proceed up the tree are: 77,000-533,000 years, 51,000-505,000 years, 36,000-639,000 years, and 16,000-571,000 years, respectively (Pruett and Winker 2008). Therefore all that can be said with a high degree of confidence is that all of the divergences probably occurred in the last half million years. It is probably also safe to say that none occurred within the present interglacial. The ranges of divergence estimates are compatible with a wide spectrum of expansion-contraction scenarios, but it is not possible to attribute them to a particular glacial or interglacial, or to recognize if the divergences are distributed randomly through the six cycles that occurred since 500,000 years ago, or if they are clustered or staggered. Nor is there a way to determine if the rates of divergence significantly differ from rates that would be observed in the absence of glacial-interglacial cycles. (They do not for mammals, for example [Barnosky 2005]). This is simply the nature of the beast: much useful information is available from coalesence modeling techniques like TMRCA, but they do not by themselves provide very strong evidence for a particular climate cycle being any more important than any other in stimulating evolutionary change.

The same holds true for the origin of and structure of haplotype diversity. It is difficult to determine with confidence details of how the pattern at one time-slice, e.g., the present, arose and how representative it is, as gene flow and population size clearly fluctuate through time. This problem can be overcome in the rare cases where fossil material of the taxon of interest is available, in an approach called phylochronology, which combines temporal with spatial genetic sampling (Hadly et al. 2004). Including just a few ancient samples increases the power of coalescent models more than adding many modern samples (Ramakrishnan et al. 2005). While such ancient samples are seldom available, it is important to recognize that where they are, they have shown how we can be fooled by interpreting history solely from the present time-slice, especially where the goal is to infer the genetic effects of climatic change (Hadly et al. 2004).

Temporal data, when available, also verify that we underappreciate how genetic diversity within and between populations moves spatially. Just because we observe certain haplotypes in a particular area is in no guarantee that the haplotypes originated there. The role of ecological sorting on the landscape may be hugely important, but is largely unknown from looking at only a single point in time.

Finally, ancillary data from geology, paleontology, and paleoclimatology also need to play a central role in phylogeographic studies that aim to understand how climatic change affects genetic structuring. Invoking generalities or 'cherry-picking' pieces of information is not sufficient. For example, to distinguish between the competing ideas of whether rock sandpipers are today caught in a refugium, or are in refugia during glacials, we need to know the distribution of ice and sea level in Beringia for the times of interest, information available from published geological work (Brigham-Grette 2001). We need to know what paleoclimate models (for example, Bartlein et al. 1998; CAPE Project Members 2001) tell about what areas might be suitable or unsuitable for rock sandpipers at relevant timesthough coarse, such information is relevant to distinguishing between the possibility or implausibility of significant southern expansions of taxa. For hypothesized areas of refugia and extirpation, we need information from the palynological record, soils, or lake deposits 
that would highlight any significant differences in habitat. Of course the best kind of data would be fossils of the birds themselves, both for direct evidence of the ancient biogeographic range and as a source of aDNA - but the absence of those fossils is not evidence that the birds were absent. Birds, especially birds like rock sandpipers, have a notoriously poor fossil record because they live in habitats where fossilization potential is low, their bones are fragile, and because there are few morphologists who are skilled at identifying fossil bird bones to the requisite taxonomic level. Lacking fossils of sandpipers themselves, another approach is to infer general biogeographic possibilities from broad suites of taxa for which we do have a good fossil record, such as those in the FAUNMAP database, as Stewart and Dalén (2008) point out.

In sum, how the next century of climatic change will affect the distribution of species is an important question from a genetic perspective. We need to be able to forecast which species will end up in refugia, which will be prone to extinction from declining genetic diversity, and which will build new diversity as their ranges expand or fragment in dynamic ways. Better integration of phylogeography (and its temporal extension phylochronology) with data from the geologic, climate, and paleontologic sciences offers a productive approach to gaining the requisite insights.

\section{References}

Barnosky AD (2005) Effects of Quaternary climatic change on speciation in mammals. J Mamm Evol $12: 247-264$

Bartlein PJ et al (1998) Paleoclimate simulations for North America over the past 21,000 years: features of the simulated climate and comparisons with paleoenvironmental data. Quat Sci Rev 17(6-7):549-585

Brigham-Grette J (2001) New perspectives on Beringian Quaternary paleogeography, stratigraphy, and glacial history. Quat Sci Rev 20(1-3):15-24

CAPE Project Members (2001) Holocene paleoclimate data from the Arctic: testing models of global climate change. Quat Sci Rev 20(12):1275-1287

Hadly EA, Ramakrishnan U, Chan YL, van Tuinen M, O’Keefe K, Spaeth PA, Conroy CJ (2004) Genetic response to climatic change: insights from ancient DNA and phylochronology. PLoS Biology 2 (10):1600-1609

IPCC (2007) Contribution of Working Group I to the Fourth Assessment Report of the Intergovernmental Panel on Climate Change: Summary for Policymakers. Approved at 10th Session of Working Group I of the IPCC, Paris, February 2007

Pruett CL, Winker K (2005) Biological impacts of climate change on a Beringian endemic: cryptic refugia in the establishment and differentiation of the rock sandpiper (Calidris ptilocnemis). Clim Change 68:219-240

Pruett CL, Winker K (2008) Evidence for cryptic northern refugia among high- and temperate latitude species in Beringia. Clim Change 86:1-2

Ramakrishnan U, Hadly EA, Mountain JL (2005) Detecting past population bottlenecks using temporal genetic data. Mol Ecol 14(10):2915-2922

Ruddiman WF (2001) Earth's climate, past and future. W. H. Freeman, New York

Stewart JR, Dalén L (2008) Is the glacial refugium concept relevant for northern species?. Clim Change $86: 1-2$

van Dam JA, Hayfaa Abdul Aziz HA, Ángeles Álvarez Sierra M, Hilgen FJ, van den Hoek LW, Ostende LW, Lourens LJ, Mein P, van der Meulen AJ, Pelaez-Campomanes P (2006) Long-period astronomical forcing of mammal turnover. Nature 443:687-691 